\title{
La subordinación del cuerpo dentro del espacio escolar
}

The subordination of the body within the school space

\section{Valeska Romero Curiqueo}

Pasarela Universitaria Horizonte Académico. Universidad de Ginebra, Suiza. ${ }^{1}$

Resumen: comprender la problemática que ejerce la norma y la disciplina sobre las personas es un punto decisivo para construir y reivindicar la propia identidad dentro de las sociedades. Esta investigación toma como punto de partida este eje, y tiene como objetivo entender como las normas escolares mediante el control y la disciplina van reproduciendo corporalidades específicas del estudiante. A través de entrevistas y observaciones identificamos las corporalidades existentes ante un cuerpo normado y disciplinado que busca espacios de resistencia y de libertad en la ausencia de las categorías de la danza en la institución escolar. .

Palabras claves: Cuerpo, educación, norma, disciplina, escuela, danza.

Abstract: Understanding the problem that the norm and discipline exerts on people is a decisive point to build and claim their own identity within societies. This research takes this axis as a starting point, and aims to understand how school rules through control and discipline reproduce specific student body. Through identifiable interviews and observations the corporalities considered before a regulated and disciplined body that seeks space for resistance and freedom in the absence of dance categories in the school institution.

Keywords: body, education, norm, discipline, school, dance.

\footnotetext{
1vvalesk.rc6@gmail.com
} 


\section{Introducción}

Las discusiones instaladas actualmente en torno a la educación son de diversa índole; ministeriales, curriculares, metodológicas, de calidad, etc. Muchas de estas demandas han sido el inicio de nuevos proyectos de intervención pedagógica, pero al mismo tiempo el debate está exento de una educación para la autonomía y la emancipación de niñas y jóvenes, a partir del desarrollo de sus corporalidades.

Un proyecto educacional de reivindicación de las identidades y el cuerpo escasea dentro del panorama curricular, por tanto incorporar el movimiento y la danza como metodologías de aprendizaje puede ser incompresible para el actual sistema educativo que no se agota en aislar el cuerpo de la mente funcional.

Muchas de estas ideas quizás jamás sean aprobadas, pero para algunos investigadores y pedagogos, el cuerpo es el inicio de las posibilidades, Le Breton, plantea que el cuerpo no solo está constituido por huesos, órganos y músculos, sino que, además consta de una carga histórica, social y cultural, donde se subscribe todo proceso. (17). El cuerpo se va originando a través de experiencias que nos llevan a generar una interpretación de los movimientos y posturas en relación a un contexto que lo modifica y transforma, a través de un marco normativo comparativo aplicable a todos los individuos.

La escuela es un territorio donde la vida de niños/as se encuentra inmersa en los planes educativos globales que establecen límites de la enseñanza. Estos limites implican disciplinamiento expresado por el control del cuerpo en la entrada a la escuela. Por ejemplo, la presencia ante el profesor, la postura corporal ante las diferentes lecciones a aprender, la posición del cuerpo durante la escritura, el control a la salida de la escuela, el uso de cierta vestimenta que determina a la institución, que a su vez caracteriza lo femenino y masculino. Todos estos elementos funcionan en la escuela como mecanismos de control.

Considerando lo anterior, también es cuestionable la ausencia en el curriculum preescrito del aprendizaje corporal el cual se encuentra enmarcado en educación física. De esta manera la danza queda reducida a otra disciplina y se materializa en la escuela cada acto folcórico. Este proceso niega y reprime la conciencia corporal que podrían generar los estudiantes en la escuela.

Dicho lo anterior para situar el debate de la escuela y la manifestación corporal de los estudiantes, es que esta investigación busca responder a la siguiente pregunta ¿Cuál es la relación entre las normativas y el desarrollo de las practicas corporales dentro de la escuela? este es el inicio para develar el cuerpo que habita y se construye dentro del sistema educacional.

La sociedad se enmarca en espacios explícitos, primero vas al colegio, sí te enfermas vas al hospital, si no sigues las leyes vas a la cárcel, si la sociedad dice que no eres sano mentalmente te encierran, cada una de estas instituciones de normalización y construcción de conductas socialmente establecidas se encuadran en tipologías de espacios para el control. Según lo señalado por Foucault, la sociedad se genera en espacios cerrados, permitiendo la vigilancia continua de los individuos por una estructura jerarquizada de vigilantes, que mediante la clasificación y el ordenamiento 
racional del tiempo y la distribución de los cuerpos en el espacio, van generando medios de control y disciplinamiento a través del "panóptico" (105).

Estás características recaen sobre la escuela, apreciando formas específicas de producción que dan cuerpo y sentido a "la institución educativa". Dicha producción construye un incesante flujo de relaciones e intereses de diversa índole, que se ven reflejados en su funcionamiento que no la hacen ser neutra. Prácticas y discursos en la escuela están sujetos a la reproducción de comportamientos arraigados en los cuerpos y mentes, imponiendo una estructura que cierra el espacio a la incertidumbre, al azar, a la improvisación. Excluye lo que no está establecido, extirpa las particularidades todas aquellas experiencias de nuestro cuerpo que no responden a los programas de enseñanza-aprendizaje.

Considerando lo anterior, se precisa debatir la naturalidad de la escuela como la única forma o sistema bajo el cual las personas se pueden educar, situándonos en su memoria histórica, sus proyectos educativos responden a fines políticos y económicos, que se insertan dentro del campo de consumo educativo perpetuador del capital regulador de la vida humana.

Por ende, muchas de sus normas y maneras de funcionar que se dan por hecho como naturales, no lo son, se olvida que la escuela y su funcionamiento es un invento del hombre, por ende, sus componentes pueden ser artificiales. En este sentido Pineau, destaca que "la escuela se convirtió en un innegable símbolo de los tiempos, en una metáfora del progreso, en una de las mayores construcciones de la modernidad" (38), además de que "su condición de naturalidad es también una construcción históricamente determinada que debe ser desarmada y desarticulada" (46).

La existencia de sujeto con el espacio es el que lo va definiendo mediante su interacción y participación con el medio, las practicas se interrelacionan con las subjetividades que vive el cuerpo así los afirman filósofos como Merleau-Ponty dan gran importancia al cuerpo como modo de participación humana en el mundo cotidiano, de donde se deriva la importancia de su localización espacial como cuerpo que lo ocupa, y su posición en relación con otros cuerpos (26)

Esta participación en el espacio como cuerpos concretos implica la necesidad inherente a la existencia de organizar el espacio en términos de la propia existencia y del cuerpo mismo como medida y referencia de todas las cosas que a todos consciente o inconsistentemente nos relaciona. El cuerpo se presenta como la unidad que comprende y capta, a través de la percepción de los sentidos, que van construyendo conocimiento, por esto, de suma importancia concebir a los estudiantes como un todo sustancial, partiendo de la concepción de cuerpo- mente como una única unidad inseparable a la hora de aprender.

Lo mencionado anteriormente, permite reflexionar sobre la forma en que el ser humano se percibe y desarrolla separadamente dentro del recinto escolar, dejando al cuerpo abandonado sobre un espacio determinista, que sigue un modelo tradicional de enseñanza centrado en el profesor, en el enciclopedismo, el verbalismo y la pasividad de los cuerpos, donde la mente cobra mayor importancia al persuadirse constantemente con los contenidos asignados, promoviendo una cultura funcional al sistema. 


\section{Sujetos desprovistos de cuerpos en el control de la norma}

Partir desde cuestionamientos y críticas al sistema actual de organización de la educación es primordial, debido a su enfoque racionalista y normativo el cual provoca la reproducción de identidades que separan al sujeto de su cuerpo, produciendo un ente sobre estructurado y simulador de sus propias características, que lo hacen identificarse a través de un patrón alienante de las conductas establecidas dentro de la moldeadora sistemática en la cual nos adentramos.

Es la norma la que genera la separación del cuerpo y la mente, generando un cuerpo constituido a partir de premisas exteriores que le confieren un valor ajeno funcional, porque ya no fluye, no se estimula, se aprisiona dentro de la escuela fuera del devenir natural de sus propios procesos, un sujeto sin cuerpo, ofrendado a la producción de su utilidad social y perfeccionado por la disciplina, Foucault, entiende al cuerpo como el lugar en donde se manifiesta la explotación total del tiempo del sujeto, para transformar todo eso en fuerza de trabajo que perpetué en el sistema y lo solidifiqué, entonces para lograr la consecución de dicha meta, se necesitan "cuerpos susceptibles de ser formados, reformados y corregidos para que adquieran aptitudes, cualidades y destrezas que lo califiquen como un cuerpo capaz de trabajar" (56).

La naturaleza en si no tiene un orden equilibrado, esto mismo se refleja en el cuerpo, el no consta de una apariencia homogénea, esta apariencia es el resultado de años de adiestramiento del cuerpo en los sistemas educacionales, que buscan cuerpos fragmentados faltos de significado, donde la uniformización juega un papel importante a la hora representar la sumisión del individuo.

Finalmente, el aula tradicional ordeno las prácticas cotidianas, sobre todo a partir del triunfo final y avasallante del método simultáneo, gradual o frontal sobre otras posibilidades en la segunda mitad del siglo XIX. La organización del espacio, tiempo y el control de los cuerpos siguió el método de organización propuesto por este último.

(Pineau 446)

Por lo tanto, se puede ver el efecto que tienen estos procesos disciplinarios bajo la población estudiantil, en el cual, no hay cabida para la diversidad y menos aún para necesidades especiales y otras formas de poder aprender o comportarse, se establece entonces un sistema cerrado que se apodera de los cuerpos, influyendo en ellos desde lo más simple, por medio de mecanismos autoritarios que están basados en el miedo. En consecuencia, el objetivo de las disciplinas fue doble, aumentar la fuerza económica del cuerpo al mismo tiempo que se la reducía en términos políticos imposibilitando la resistencia o la rebeldía. 
El cuerpo humano entra en un mecanismo de poder que lo explora, lo desarticula y lo recompone. Una "anatomía política", que es igualmente una "mecánica del poder" está naciendo; define cómo se puede hacer presa en el cuerpo de los demás, no simplemente para que ellos hagan lo que se desea, sino para que operen como quiere, con las técnicas, según la rapidez y la eficacia que se determina. La disciplina fabrica así cuerpos sometidos y ejercitados, cuerpos dóciles. (Foucault 141).

El sistema educativo actual encubre muchos errores, invade cuerpos deseosos de crear, transformándolos en cuerpos obedientes que no piensen por sí mismos, en este sentido no es extraño que la incorporación de materias referidas al uso del cuerpo como instrumento pensante, prácticamente no existan en los currículos de los colegios, salvo educación física que es más bien, un entrenamiento militar similar al de los curiosamente llamados "uniformados.

El ambiente escolar debe proporcionar libertad por medio del equilibrio de la relación existente entre el medio y el sujeto. Esta unión permiten que los estudiantes desarrollen una visión colectiva, habitada y apropiada del espacio escolar, ya que logrando este importante punto los niña/os internalizaran sus experiencias de vida, dotándolas de significado y sentido debido a la realidad que perciben, situándose en un proceso dialectico de vinculación constante, esto quiere decir al mismo tiempo que se apropian de la escuela, también la veneran.

Lograr el pleno desarrollo de la persona requiere de un ambiente escolar propicio, dinámico, diverso, abierto, claro en oportunidades y no discriminatorio, donde tengan cabida todos y donde se favorezca la valoración de la diversidad en un respetuoso convivir (Sacristán 173).

\section{Planteamientos pedagógicos desde el cuerpo en movimiento}

Se avanza hacia el reconocimiento del estudiante, como un ser humano cargado de derechos y subjetividades, un ser "en construcción" movilizado por las experiencias que lo constituyen y posicionan como una entidad única. La institución escolar se configuró como el dispositivo que se construyó para encerrar el cuerpo, no sola mente en un edificio, sino también en un aula y en un banco escolar. Estas categorías situaron al cuerpo en un lugar de plena heteronomía. Por lo que es ineludible crear enfoques educacionales donde los procesos educativos informales sean integrados sinérgicamente con los procesos formales, especialmente cuando los últimos no han podido garantizar la calidad y equidad del sistema escolar. 
Como una propuesta de un nuevo enfoque educacional es el sentido revolucionario que propone Reclus, así como el proceso formativo se entiende en un contexto de cambio y transformación de un algo. Así evolución y revolución serian el campo donde se presenta una nueva noción pedagógica, ya que desde la tesis de Reclus, estas dos palabras están totalmente relacionadas en la acción de una nueva visión continua y en movimiento. "Una revolución cualquiera es siempre buena cuando se produce contra un amo o contra un régimen: pero si de ella ha de surgir nuevos despotismos" (11). Educación y revolución se completan mutuamente: un educador no puede olvidar todo lo que la educación debe a la revolución, así como un revolucionario consciente seguramente no puede olvidarse de la educación, "Una revolución no se hace sin revolucionarios y el individuo revolucionario es, de alguna manera, un producto de la educación” (9)

Preparar una revolución significa aumentar la necesidad de ésta entre los individuos, despertar los sentimientos de las masas para que tomen conciencia. La obra educativa es entonces fundamental para obtener un resultado positivo en sentido libertario. Los procesos educativos escolares formales son una re- elaboración hecha a partir de procesos educativos informales, gracias a lo cual pierde parte de su riqueza educacional y pertinencia cultural.

Freinet (1982) representante de la pedagogía moderna nos demuestra como a través de métodos naturales y de una propuesta en donde el tanteo experimental es la pieza clave para lograr aprendizajes significativos, el estudiante en "la espontaneidad de la vida por tanteo orientado, adquiere los medios de expresión que son las herramientas de aprendizaje" (11). Es el individuo que debe forjar sus propias herramientas adherirlas a todo su ser integrarlas en los reflejos y en los automatismos profundos de su maquinaria física y síquica. Entonces la herramienta conscientemente creada y que responde a las necesidades profundas del ser permitirá construir sólidamente mediante sucesivos andamiajes el edificio de la personalidad.

Resignificar el cuerpo y ciertas partes de este, las emociones y sensaciones los usos del cuerpo en el espacio y en el tiempo, se convierten en acciones prioritarias para cualquier desafío pedagógico y escolar. Quizás valga la pena animarse a construir nuevos sentidos y significados del y sobre el cuerpo, ampliando la voz y la sensibilidad a aquellas corporalidades que han sido sistemáticamente silenciadas, omitidas, sometidas y excluidas dentro del marco educacional.

\section{Metodología}

Esta investigación posee un enfoque cualitativo, para ello se pretende decodificar la realidad a través de la percepción y experiencia de los sujetos de estudio. La investigación se desarrolla en un colegio del sector sur de la región metropolitana. La entrevista, como técnica de recolección nos permite comprender la realidad, adquiriendo por medio de los relatos verbales, información relevante para establecer las dinámicas cuestionadas. Se realizarán entrevistas semi-estructuradas de carácter personal a los actores que habitan el espacio escolar, respondiendo al enfoque cualitativo que se hace oportuno en toda nuestra investigación. El grupo de discusión se realizó a jóvenes de $3^{\circ}$ medio, constituyéndose como información principal para esta investigación, ya que las reflexiones y pensamiento de los alumnos son un eje importante de este proceso debido a la relación directa en que viven con las normativas. Para lograr analizar la información necesaria que nos proporcionaran las ideas colectivas del cuerpo que habita el espacio escolar. 


\section{Análisis}

\section{¿Cómo creamos al alumna/o? El menor categorizado y clasificado por los rasgos esenciales que controlan el cuerpo.}

El adolescente va adquiriendo sentido según las experiencias singulares en la que se encuentra, a través de cuerpos heterogéneos que experimentan en relación a la realidad sostenida por los adultos. Dos mundos en contraposición debido a un pensar racionalista e instrumentalista de los adultos ya formados, opuestos al espíritu juvenil libre, abierto, disponible y carente de orden, así es que el adolescente aprende a ser alumna/o en contraposición a la vida del adulto dejando a un lado el respeto al autoconocimiento y la propia identidad, ya que "el ser humano elaboró y utilizo tipologías de personas y edades diferenciadas para comprender el proceso del desarrollo humano y situar a los individuos en algún punto" (Sacristán 75).

Como diría Sacristán, nosotros poseemos un bagaje cultural colectivo de la genealogía del menoralumno, creando naturalmente la realidad ficcionaria de este, que es propio del adulto generador de discursos socioculturales imparciales, dotando categorías que se implantan al menor, "ser alumno ha sido y sigue siendo una experiencia y una condición social fundamental de los menores" (80) donde la institucionalización cobra sentido en la construcción del adolescente.

Los actores reconfiguran esta realidad, por un lado, nos proporciona un perfil el cual se "debe ser", en la postergación de la "del ser", así la siguiente cita de entrevista da cuenta de esta situación:

El perfil tiene que ver con la normativa también y con la visión con la que el colegio trata, un perfil del alumno que tiene que ser educado, que se rige con las normas del colegio, tener su uniforme que corresponde, tener buen rendimiento, ósea como el lema que tenemos nosotros ser siempre el mejor. (E.2.19).

Desde su propia perspectiva los involucrados disciernen una homogenización desprovista de las capacidades naturales que cada quien posee por una prohibición de desarrollarse en ámbitos desiguales al orden normativo, carente de un sentimiento que como jóvenes los hace felices ahora y en un futuro. La siguiente cita apoya esta idea:

Encuentro que si hubiéramos tenido más espacio recreativo desde chico muchas personas aquí hubieran salido, con algún talento, como un talento natural por ejemplo; tocar la guitarra, si hubieras podido aquí expresar ese capacidad muchas personas habrían tenido una personalidad diferente (E 3.19). 
La idealización de convivencia entre el cuerpo y la escuela constituye una distinción necesaria para identificar al alumna/o que como hemos analizado la presentación, las normas, el rendimiento; controlan y reprimen a los cuerpos faltos de organicidad, constando de constreñimiento a la integralidad multifacética de los cuerpos sensibles.

La referencia de la cita, da cuenta de la existencia de un mecanismo de control que se interioriza en el cuerpo proyectando dependencias a un sistema educacional obligatorio, que no es más que un consumo de órdenes que deshabitan el cuerpo en superficialidades. Otro aspecto importante que nombran los adolescentes se refiere a la perdida de la felicidad, quizás por el miedo al desprendimiento del orden social, escolar, contaminador de goce innato de relacionarse, de soñar una vida distinta sin límites, de crear espacio íntimos e identificatorios, en un fin de expresión libre. Es en este análisis que podemos dar cuenta de la existencia de un cuerpo sensible que pese a la condición física que le otorga la escuela, de todas maneras se reconoce una corporalidad en sus elementos culturales y políticos (Le Breton 27 )

\section{El dialogo jerárquico de los actores educativos}

Desde una perspectiva educacional nos asentamos en la primordialidad que tiene el acto comunicacional y su consiguiente interacción con el entorno y las personas que participan en este circuito. Así el análisis llevado a cabo en el colegio permite esclarecer cómo funciona el ser en comunicación dentro de la estructura escolar, encontrándonos con una peculiaridad en el modo en que interactúan los sujetos en el espacio escolar.

Al entrevistar al inspector podemos conocer la forma en la que se enfrentan los conflictos al interior de la institución, formulando una idea de jerarquización de las relaciones, ya que se instalan conductos regulares en la intervención de los problemas de la comunidad:

Por ejemplo, pueden a ver conflictos en los cuales interactúan dos personas que no son de la misma jerarquía, entonces hay se aplican distintas estrategias, digamos si un conflicto entre dos alumnos cierto, hay tu aplicas una mediación pero si dos personas esta jerárquicamente será al mismo nivel cierto, pero que pasa cuando hay conflicto entre un profesor y un alumno, hay es distinto hay tú tienes que hacer un arbitraje porque es distinto la mediación, me entiende entonces son distintas las técnicas de mediación que se van utilizando de acuerdo al conflicto que se vaya dando y obviamente la mediación parte de una primera etapa porque ya después viene la sanción (E.2.1). 
Esta jerarquización, genera una escala de posiciones en que cada uno ocupa un lugar y se reconoce en él de no ser así, existirá la sanción, conductora del miedo al castigo, a la autoridad y la culpabilidad por herrar en tal acto. Continuando la línea del análisis podemos integrar las palabras de Foucault, que nos menciona las relaciones de poder que regulan y califican la interacción entre los sujetos, conllevando a una serie de prácticas coactivas (141). Sin duda, unos de los elementos que nos lleva a la jerarquización, menciona este autor es la intervención del poder, lo que en esta caso sería la sanción. El poder no solo reprime, sino que también produce, efectos de verdad, de saber, en el sentido del conocimiento. En relación a esta premisa, la siguiente cita de un entrevistado, nos entrega luces de cómo esta idea se puede materializar:

Creo que más importante que los alumnos estén de acuerdo, es más importante que los apoderados estén de acuerdo por que los alumnos son los que se están formando no solo en formación, solo educando, acá ellos no son garantes de sí mismo, me entiende, nosotros estamos encargados de ellos y tienen un apoderado que es la persona que se encarga de ellos (E.2.5).

En construcción de base piramidal logra influenciar a los menores, en este contexto, la autoridad será personificada por el inspector y el profesor. Respecto a esto los alumna/os se refieren y valoran a la autoridad, desde una perspectiva de respeto a, una persona que es mayor que ellos. El entrevistado Otra entrevista indica como, una de las alumnas se replantea la relación que sostiene con sus profesores, enmarcando que el respeto es un valor mutuo entre las personas, en donde se comprende y se valoran proponiendo una construcción colectiva, estos se diferencian a lo promulgado por el inspector. Desde este surgimiento es que los alumna/os reflexionan nuevamente en una dialéctica en comprensión de su realidad, así queda en claro en la cita a continuación:

Yo creo que sería una relación más de confianza que de respeto, porque el respeto siempre va a hacer a si...muchas veces le llaman respeto, pero es más miedo a lo que puedan hacer ellos a uno, no es como un respeto a sí. o hay que dejarse pasar a llevar, el respeto se gana ...no es por admirar a esa persona, sino solo miedo por lo que puedan hacer cachay no es respeto (E.3.12). 
Aparece un punto muy importante en esta cita, el miedo como constructor de las interacciones entre los sujetos educativos; el miedo se constituye de sensaciones de desconfianza e inseguridad en presencia de algún peligro, es abrumador pensar que niñas y niños que se encuentran en la escuela se movilizan a través del miedo. El miedo a la autoridad se va caracterizando en esta escuela por la presencia de una vigilancia directa hacia los estudiantes, por lo cual se administra castigo en la mala actuación de los jóvenes, con el deseo de imponer normas.

De tal manera, los jóvenes desde un sentimiento de miedo empiezan a construir el "cuerpo sumiso" expuesto a la voluntad de la autoridad posibilitadora del ejercicio de la norma. El cuerpo sumiso asume los dictámenes planteados desde el exterior, interiorizando en él prácticas habituales de obediencia a la autoridad. Considerando la forma en que él castigo se incorpora a los adolescentes, es que se puede registrar en este análisis el cuerpo sumiso de los entrevistados.

\section{Las normas que crean-producen a la institución escolar}

En el establecimiento escolar existen actores muy particulares como es el inspector general, aquel individuo que relaciona con el lema del buen convivir armónico. Desde el inicio de nuestra entrevista este actor educativo enfatiza lo fundamental que son las normas para la constitución de la escuela y la organicidad del conjunto de sujetos, esta cita da cuenta de esta situación:

Los protocolos se hacen de acuerdo con los estándares que nos entregan el ministerio de educación, el Mineduc, en este caso bueno se trabaja digamos en nivel de alumno, cierto ósea a nivel de la educativa completa, ya mediante de las relaciones que se dan entre los alumnos u otros afectos de la comunidad educativa (E.2.1).

Asimismo, expone los lineamientos específicos del reglamento interno, adjudicándose a tres ejes; conducta, disciplina y rendimiento.

Para mi trabajo, todas las que tienen que ver con la parte conductual y de disciplina digamos de que no es lo mismo ya de la parte conductual claro, la parte conductual digamos tienen que ver mucho como dice la palabra con la conducta del alumno dentro del aula y dentro del establecimiento, (...) la parte digamos disciplina lo atrasos que asistan a clase cierto que no lleguen atrasados que vengan con su uniforme completo que tengan un vocabulario adecuado más o menos en ese punto estoy y el tema del 
VALESKA ROMERO CURIQUEO. • La subordinación del cuerpo dentro del espacio escolar

rendimiento es claramente las notas, cierto que tenga claro que tengan un buen rendimiento (E.1.3).

Por medio de estas líneas podemos comprender las particularidades en que se dividen estos reglamentos y sus posibles líneas de acción, ante esto se destaca el carácter evaluativo de rendimiento en los que se categoriza a los estudiantes, presuponiendo un modelo inductivo a desarrollar para conseguir la anhelada excelencia académica.

Presentada ya la descripción del inspector es que nos aproximamos al de un profesor que a través de la pregunta ¿Crees que es importante que tus alumnos conozcan y estén de acuerdo con las normas?, responde lo siguiente:

Totalmente es fundamental que ellos saber por qué uno le exige las cosas, saber por qué es necesaria la disciplina, saber por qué es necesario que lleguen a la hora porque no tienen que perder clases porque tienen que estar bien vestidos también ósea todo tiene su explicación y mientras ellos estén al tanto de eso es fundamental para que resulte bien (E.2.5).

Desde otro polo aparecen las interpretaciones de los estudiantes respecto a los reglamentos desdiciendo y rechazando algún conocimiento de la construcción colectiva de estas, de hecho, cuando se les pregunta el nexo que tienen, quedan los cuatro estudiantes en silencio sin saber que responder, dando a entender que no existe una reflexión, ni las instancias necesarias para el conocimiento de los reglamentos en los cuales se constituye su escuela.

La participación que ellos tienen la conciben en un primer acercamiento como lo mencionan a continuación:

De cierta forma si cumpliéndolas, si...no las siguiéramos las normas no habría normas muy específicas porque si no la siguiéramos de que serviría. Yo creo que a veces preguntan, pero casi nunca toman la opinión de uno. 
Igual a veces nos piden que movamos alguna prueba o algo así hay veces que considera nuestra opinión, pero tampoco es que la tengan muy en cuenta. La damos, pero no nos toman muy en cuenta (E.3.5).

En síntesis, los alumnos expresan que existe una nula participación en la creación de su escuela, apareciendo también lo poco consientes que son en esta primera etapa de la entrevista, del como la escuela influencia en su desarrollo como sujetos.

El alumno no tiene la autorización de crear normas, a lo que tienen derecho es a intervenir lo establecido con pequeñas acciones que desestructuran a los estudiantes como andar con ropa de colores no establecidas, junto a esto aparece entonces el sentimiento de pertenencia a la escuela que el estudiante tiene.

A mí sí me gusta el colegio porque es como un lugar donde puedes compartir con tus amigos, y aprendí y todo, pero no sé si me gustan las normas que tienes que ser así y así y cumplir esto, esto y esto si no así esto no puedes hacer esto otro (E.3.7).

La escuela se presenta como una invención cultural que responde a un proyecto social de orden, en evolución favorable de las condiciones económicas regidas por un sistema capitalista que somete a los individuos a la interiorización de una serie de normas. Esta ha mostrado una gran capacidad para instalarse y desarrollarse en la sociedad sin cambiar sus bases que rigen desde hace mucho tiempo. Así es que el estudiante al mismo tiempo que le dicen que debe hacer, también valora el espacio educativo, pues en él encuentra amistad. Así es como emerge el cuerpo funcional realizando actividades desde una práctica útil de comportamiento respondiendo a los reglamentos internos y ministeriales. La funcionalidad se activa, por la frecuente repetición de la conducta, "cuerpo funcional" una conducta positiva para la escuela conducida desde las perspectivas de mejora y eficacia de los cuerpos. El cuerpo se ha encontrado al centro de la sociedad a costa de las exigencias de las políticas neoliberales, menciona Tijoux (2010), así es que este cuerpo funcional es generado por la escuela.

\section{Espacio temporal, normas implícitas}

A través de la investigación podemos dar cuenta de que existen normas implícitas ignoradas, que apagan la conciencia, dando poder a dirigir y controlar los actos de las personas desde una perspectiva camuflada e inconsciente. El profesor de educación física y el inspector comienzan a realizar un enunciado de estas:

Bueno la norma principal de acá se rige mucho envase a la disciplina en cuanto a respetar lo horario de clases, lo horario de entrada y salida así como los de recreo, 
fundamentalmente que el horario de clase se cumpla, como tal, que no se pierdan horas en salir al baño o en salir hacer cualquier otro tipo de actividad y que se aproveche la clase lo máximo posible.

El perfil tiene que ver con la normativa también y con la visión con la que el colegio trata, un perfil del alumno que tiene que ser educado, que se rige con las normas del colegio, tener su uniforme que corresponde tener buen rendimiento, ósea como el lema que tenemos nosotros ser siempre el mejor (E.2.15).

Al encontrar estos puntos conducimos, cada tarea, actividad como representaciones de las formas de utilizar el tiempo y el espacio en productividad del desarrollo de los sujetos, del orden escolar y de la prevalencia social. El respeto al horario, el uniforme, el rendimiento, la visión de colegio son expresiones que nos instala en un fin determinado por la producción del tiempo y la dependencia al espacio escolar.

En sí, el espacio escolar se materializa por medio de una estructura edificada que se hace presente, pero que sin duda en su interior contiene una cantidad de elementos simbólicos. Así podemos considerar que el edificio como tal, es parte de un sistema comunicativo en donde se cumpliría la función de contenedor físico de los significados normativos de la estructura de esta escuela. Tales significados son evidenciados a través de su diseño y materialidad, los cuales circunscriben a sus ocupantes desde la espacialidad y orientan sus comportamientos desde la funcionalidad. En general, en toda institución las actividades son reguladas para el logro de sus objetivos. Tales regulaciones afectan la situación y ocupación del espacio y norman las actividades del cuerpo del sujeto. De tal modo, nos podemos dar cuenta como la presentación personal es un hecho transcendental para habitar la escuela, sin duda es un acto condicionante "No me siento cómoda no me gusta cómo usar falda todo el rato, no me gusta usar pantalón, no me gusta usar esta polera no me gusta, parecemos como si fuéramos a un funeral, a si todos iguales" (E.3.15).

El establecimiento escolar va generando cuerpos escolarizados. Aparece justamente una sensación de encierro reforzada en dos direcciones sobre sus cuerpos con el uniforme y con el espacio donde se desenvuelven, aparece una uniformidad corporal y espacial. La experiencia que tienen los estudiantes dentro de la escuela es parte una sensación estática y monótona, en la siguiente cita lo manifiestan:

Un lugar cuadrado, sinceramente yo lo siento como tipo cárcel, lo encuentro como muy rústico, no sé, como una construcción muy antigua que no tiene como, algún tipo de diseño, es como todo cuadrado y derecho que le dé algo, como más llamativo, que lo 
encuentro todo como muy, ¡ya! una sala cuadrada, un espacio cuadrado. Todo cuadrado, no es como un lugar como bonito (E 3.6).

Esta concepción de encierro que tienen los alumnas/os al permanecer en el espacio de su escuela, lo podemos vincular con los planteamientos expuestos en nuestro marco teórico respeto lo dicho por Foucault, el edificio institucional, el colegio entre otros, es un espacio de control dentro de otros mecanismos en la tecnología del poder que desarrollan la institución, y cuyos destinatarios son los sujetos que les ocupan (141). Justamente teniendo un espacio de encierro y de control como el panóptico, es que, los espacios se regulan, siendo visibles al ojo de la autoridad que debidamente permite un control visual, la vigilancia de todos aquellos espacios de la escuela, desde este panorama es que el inspector asegura su rol de autoridad y vigilancia, así lo advierte en la siguiente cita :

Ósea no hay que dejar espacio donde los chiquillos se puedan esconder o salas donde los profesores también, o cualquier persona ósea, yo no ataco nadie, pero cualquier persona puede ser un potencial agresor, entonces hay que cuidar los espacios, no dejar el espacio a la duda (...) entonces esta es una tranquilidad para los apoderados y también es una regulación para alumnos porque saben que lo están observando (E.2.11).

No obstante, esta perspectiva tiene completa relación con el panóptico que vigila, controla y castiga a los dominados en este caso los estudiantes. Este entorno espacial es muy poco consciente en cuanto influye en nuestro actuar. El espacio es un contenedor de nuestro lenguaje corporal y desde ahí la proyección de nuestro ser, significa al igual un medio de vinculación, en este caso de dominación del moldeamiento de la construcción de jóvenes que como menciona el inspector "no hay que dejar espacio a la duda" y desde aquí es que existe una desvinculación del espacio como un territorio creativo de apropiación.

Por parte de los estudiantes se escabullen del espacio que los norma "nos escondemos atrás, en los muebles, nos acostamos a dormir un rato no tapamos con las cotonas". El hecho que las/os jóvenes deban esconderse para su actuar, nos habla de una fragmentación que suscita entre ellos y su entorno espacial escolar, el cual los desvincula inmediatamente a la hora de condicionarlos tan severamente al orden escolar que se despreocupa de sus prácticas corporales. 
Visto de esta manera y sumando las implicancias que tiene el ambiente en las experiencias y comportamiento de los sujetos de acuerdo a la psicología ambiental. El edificio escolar así diseñado y distribuido modela por sí mismo y prácticamente sin contrapeso el comportamiento de las/os estudiantes conduciendo sus actividades conforme ocupa los espacios, un estudiante manifiesta: "Es que en el colegio es todo cuadrado tienes que estar sentado mirando para delante y bien sentado y con el cuaderno y mirando pal frente no te puedes mover si te paras te retan". Agregan además que existe una escases en la instancia de generar espacio recreativos

Yo creo que nos falta libertad de expresión, proponemos ideas cosas y la directiva nos niegan la mayoría de las cosas, entonces tenemos que ver y cuadra cosas que relativamente sirvan para el alumno, ¿Qué han expresado?, por ejemplo, de que queríamos sacar al colegio por cursos a paseos interactivos empresas, museo, con el tiempo se han ido desgastando, no se abren nuevos lugares (E.3.9).

Existe un observador, la autoridad institucional que regula sus actos. En esta observación permanente, los cuerpos escolarizados son tratados como cosas que pueden ser examinadas libremente por la institucionalidad. Esta exhibición representa un alto grado de violencia en la relación de poder, ya que tales sujetos son despojados de la intimidad que es inherente, desnudados en su privacidad.

El cuerpo escolarizado ocurre cuando la persona, sus acciones y todo su cuerpo, se enclaustran dentro de la red de relaciones del mundo escolar cuando se aprende a adaptar a un ambiente donde todo parece ser dogmático. La escuela se ha empeñado en mantener un cuerpo escolarizado en que los estudiantes deben tener determinada postura, y deben estar en las mejores circunstancias cuando se trata de recibir clases.

\section{Cuerpo y tiempo en la escuela}

La escuela regula distintas actividades sujetas a un tiempo determinado, pauteando las acciones de los sujetos, un ejemplo de ello es la siguiente cita:

Bueno la norma principal de acá se rige mucho envase a la disciplina en cuanto a respetar el horario de clases, el horario de entrada y salida, así como los de recreo, fundamentalmente que el horario de clase se cumpla, como tal, que no se pierdan horas 
en salir al baño o en salir hacer cualquier otro tipo de actividad y que se aproveche la clase lo máximo posible (E1.1).

Se puede entender en este discurso que el ritmo académico es indispensable, asimismo se devela una categorización de las actividades temporales, cada acto tiene su tiempo y acción determinada, surge entonces que quien no aproveche y no se desarrolle adecuadamente en cada sección temporal, no cumplirá con las expectativas promulgadas. En fin, expuesto este discurso expresado por el profesor de educación física, antes de responder sobre la educación y conciencia corporal, da a entender como el universo corporal infinito queda arrestado a un patrón:

Ósea si uno quisiera tener una clase exitosa necesariamente requiere de los tiempos bien catalogados para poder hacer la clase”. ¿Entonces para ti la clase "exitosa" estaría relacionada con los horarios?, Claro porque uno lo planifica en base al tiempo, también hace cada planificación, uno tiene en el inicio unos diez minutos, en el desarrollo ya tiene un poco más cuarenta minutos y en la puesta final cinco minutos más, ya, entonces si se respeta eso la clase resulta exitosa (E.1.3).

A partir de la cita, cabe preguntarse, por qué el profesor organiza su clase entorno al tiempo y no abarca la idealización de trabajar con consignas corporales, en otras palabras se va imposibilitando la escucha corporal y silenciando la motricidad comunicativa, creativa y disfrutable, por la formación positivista y empírica de este profesor que no permite ni es consciente de impulsar este acto corporal.

El tiempo expresado por el inspector nos habla de un ritmo analógico común para todas/os y su justificado aprendizaje aparece en el momento de la colectivización debe avanzar en conjunto respondiendo al tiempo regulatorio tanto colectivo como personal, ya que, aquellos que no se suman adecuadamente a las actividades y al rendimiento necesario son insertos en reforzamiento. Así es que este cuerpo de estudiante se reduce a sus dinámicas temporales, siendo este el cuerpo explotado, privando al sujeto de conocerse así mismo al otro, como también la necesidad de escucharse y escuchar del educador.

Considerando lo anterior, podemos señalar que las normas de comportamiento del establecimiento educacional, tal cual la declaran los/as entrevistados, persiguen un efecto en sus voluntades: autocontrol, seguimiento de normas, internalización de pautas de comportamiento, preparación para la inserción laboral, etc. 


\section{Conclusiones}

Los cuerpos de los estudiantes en la institución escolar se grafican a continuación:

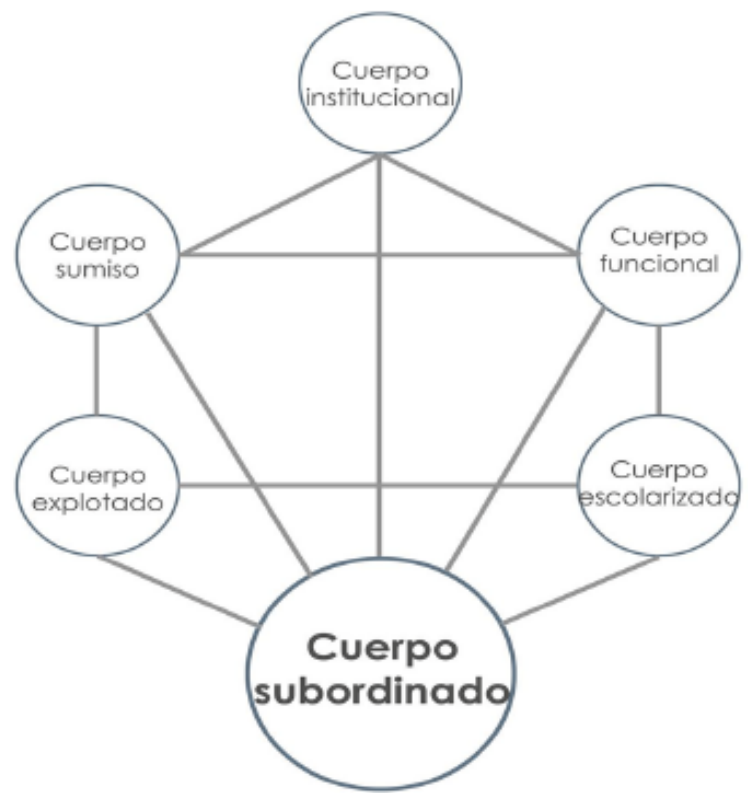

Fuente: elaboración propia

Los cuerpos que se indican en la imagen se crean a partir de la relación de este con la normativa institucional de la escuela. Las normas derivan de un discurso hegemónico de validación que manifiesta metas y objetivos acotados entre lo pre- escrito y lo posible que cabe por hacer. Una actitud un lema una visión paradigmática que ocupa a la norma como herramienta de construcción.

La norma es a la escuela, como la escuela es a la norma, esta se manifiesta a través de una relación directamente proporcional, que propone espacios de participación y expresión. Asimismo lo vemos en creación de los conductos regulares, ministeriales e internos que se reducen a imposiciones que evidencian el nulo contenido de representaciones colectivas que suceden particularmente en el espacio-tiempo escolar.

La institucionalidad impone su voluntad en todo ámbito, el tiempo es cronometrado en cada actividad restringiendo los ritmos escolares; horarios, ciclos, niveles, entradas, salidas, descansos, referentes, de un sistema de organización de las unidades de producción y eficiencia claves para la enseñanza.

Así, las prácticas generadas por la escuelas en una instancia niegan la presencia del cuerpo con capacidad creativa porque los inserta en un margen establecido de acciones y comportamiento arraigados que toman la decisión de conducir los cuerpos juveniles. Desde esta perspectiva, el estudiantado, como cuerpo exhibido, se encuentra limitado en el consciente objetualizado de sus experiencias compuesto por las prácticas y normativas encaminadas al sedentarismo, a la inamovilidad, a la dependencia del actual sistema, que dificulta el cuerpo apropiado, liberado de 
todo sistema de control y sumisión. De esta manera, la posibilidad de los estudiantes de establecer una formación autónoma o auto responsable queda supeditada a la norma.

Dicho esto, la escuela es una maquina institucional de leyes ministeriales e institucional que enjuician sin ningún valor al cuerpo juvenil, suprimiéndolo. Finalmente la forma en que los cuerpos en la escuela son determinados a partir de la norma, dan cuenta de la importancia de la danza entendida como un proceso la cual debe dejar de ser mirada para un espectáculo, el cuerpo de la danza debe ser para la vida, un cuerpo en movimiento presente sensible y humano. Esa transformación de cambiar al cuerpo subordinado por medio de la danza implica una emocionalidad, ese enamorarse de la experiencia que pasa por la introspección aún en la acción y que tiene que ver con un sentido más del cuerpo que no es anatómico, superficial, pero si vital y hasta holístico permitiendo que el cuerpo tenga esa disposición hacia el aprendizaje y al desarrollo de sus propias potencialidades. 


\section{Bibliografía}

Agamben, Giorgio. ¿Qué es lo Contemporáneo?. Este texto, inédito en español, fue leído en el curso de filosofía teocrática que se llevó a cabo en la facultad de Artes y Diseño de Venecia entre 2006 y 2007.Traduccion: Verónica Najera 2008

Bakunin, Mijail. Escritos de filosofía política V. I. Madrid: Alianza., 1978. Impreso.

Fontaine, Geisha. Las danzas del tiempo. Centro cultural de la cooperación floreal Gorini, Buenos Aires, Argentina. 2012. Impreso.

Foucault, Michel. Vigilar y Castigar: nacimiento de la prisión. México, D.F., México: Siglo XXI, 1976. Impreso.

Freinet, Celestine. Técnicas Freinet de la escuela moderna. México, D.F, México: Siglo XXI, 1987. Impreso

Grasso, Alicia. Construyendo identidad corporal, Ediciones novedades educativas, Buenos Aires, Argentina. 2005. Impreso.

Le Breton, David. Cuerpo sensible. Santiago de Chile, Chile: Metales pesados, 2009. Impreso.

Pineau, Pablo. La máquina de educar. Buenos Aires, Argentina: Paidós, 2003. Impreso.

Merleau-Ponty, Maurice, 1908-1961. Fenomelogía de la percepción. London : New York :Routledge \& K. Paul; Humanities Press, 1974. Impreso.

Ranciere, Jacques. Centro coreográfico Galego, Universidad de Alcala. España, 2009. Impreso.

Recluse, Élisée. Evolución revolución y anarquía. España: Itaca, 2014. Impreso.

Sacristán, Gimeno. El alumno como invención. Madrid, España: Morata, 2003. Impreso.

Incorporar cuerpos contemporáneos.

Tijoux, Maria. Cuerpos contemporáneos: nuevas prácticas, antiguos retos, otras pasiones. Chile, Santiago: LOM, 2010. Impreso.

Recibido: 12 de Septiembre de 2019

Aceptado: 1 de Octubre de 2019 